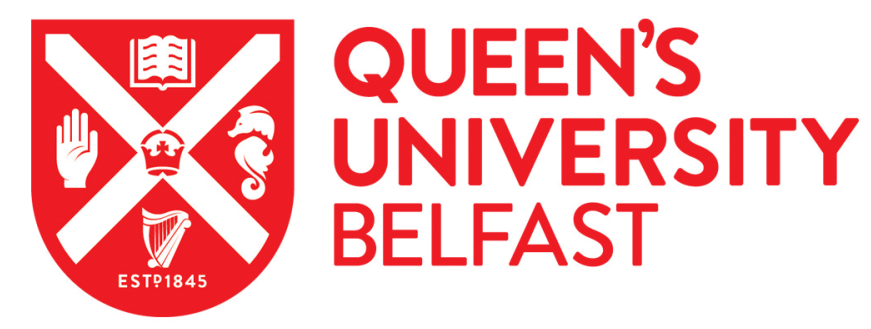

\title{
Placental vascularization indices and prediction of pre-eclampsia in high-risk women
}

\author{
Eastwood, K-A., Hunter, A. J., Patterson, C. C., McCance, D. R., Young, I. S., \& Holmes, V. A. (2018). Placental \\ vascularization indices and prediction of pre-eclampsia in high-risk women. Placenta, 70, 53-59. \\ https://doi.org/10.1016/j.placenta.2018.09.005
}

\section{Published in:}

Placenta

\section{Document Version:}

Peer reviewed version

Queen's University Belfast - Research Portal:

Link to publication record in Queen's University Belfast Research Portal

\section{Publisher rights}

Copyright 2018 Elsevier.

This manuscript is distributed under a Creative Commons Attribution-NonCommercial-NoDerivs License

(https://creativecommons.org/licenses/by-nc-nd/4.0/), which permits distribution and reproduction for non-commercial purposes, provided the author and source are cited.

\section{General rights}

Copyright for the publications made accessible via the Queen's University Belfast Research Portal is retained by the author(s) and / or other copyright owners and it is a condition of accessing these publications that users recognise and abide by the legal requirements associated with these rights.

Take down policy

The Research Portal is Queen's institutional repository that provides access to Queen's research output. Every effort has been made to ensure that content in the Research Portal does not infringe any person's rights, or applicable UK laws. If you discover content in the Research Portal that you believe breaches copyright or violates any law, please contact openaccess@qub.ac.uk. 
Title

Placental vascularization indices and prediction of pre-eclampsia in high-risk women

\section{Author names and affiliations}

1. Kelly-Ann Eastwood ${ }^{1}$

2. Alyson J Hunter ${ }^{1,2}$

3. Christopher C Patterson ${ }^{1}$

4. David R Mc Cance ${ }^{1,3}$

5. lan $S$ Young ${ }^{1}$

6. Valerie A Holmes ${ }^{1}$

\section{Institutional affiliations}

${ }^{1}$ Queen's University Belfast, Centre for Public Health, Institute of Clinical Sciences, Block B, Royal Victoria Hospital, Belfast, BT12 6BA

${ }^{2}$ Royal Jubilee Maternity Hospital, 274 Grosvenor Road, Belfast, BT12 6BA

${ }^{3}$ Regional Centre for Endocrinology and Diabetes, Royal Victoria Hospital, 274 Grosvenor Road, Belfast, BT12 6BA

\section{Corresponding author's contact information}

Dr Kelly-Ann Eastwood

Office 01.010,

Centre for Public Health, Institute of Clinical Sciences, Block B,

Royal Victoria Hospital,

Belfast,

BT12 6BA

United Kingdom

Tel (work): +44 (0) 2890235900

Tel (home): +44 (0) 7799253635

Email: keastwood01@qub.ac.uk

\section{Conflict of interest statement}

The authors report no conflict of interest 


\begin{abstract}
Objective:

To assess ability of first and second trimester Placental Vascularization Indices (PVIs); Vascularization Index (VI), Flow Index (FI) and Vascularization Flow Index (VFI) to predict pre-eclampsia (PE) in high-risk pregnancies.
\end{abstract}

Method:

PVIs derived from 3-Dimensional power Doppler imaging were measured at $11+0-13+6$ $(n=194)$ and 19+0-21+6 weeks ( $n=195)$. Logistic regression (LR) models used PE as the outcome. To quantify added value of PVIs to baseline characteristics in predicting PE, integrated discrimination improvement (IDI) and net reclassification improvement (NRI) indices were calculated.

Results:

Overall rate of PE was $12 \%(n=26)$. Lower first trimester PVIs were seen in women with PE (mean, SD); VI (\%): 10.0 (6.2) v 14.7 (7.6), P=0.005, FI: 37.7 (9.1) v 42.9 (10.4), P=0.03, VFI: $3.8(2.5) v 6.6$ (4.0), $\mathrm{P}<0.001)$. All first trimester PVIs predicted $\mathrm{PE}$ in $\mathrm{LR}$ models adjusted for covariates. IDI and NRI analyses confirmed added clinical utility of VI (IDI 0.054, P=0.004; NRI 0.66, $\mathrm{P}<0.001$ ) and VFI (IDI 0.061, $\mathrm{P}=0.004 ; \mathrm{NRI} 0.53, \mathrm{P}=0.91$ ). In the second trimester, $\mathrm{FI}$ was lower in women with PE (39.6 (9.1) v 44.4 (8.6), $\mathrm{P}=0.01)$ and predicted PE in adjusted LR models (standardised $\mathrm{OR} 0.53,95 \% \mathrm{Cl} 0.29-0.97, \mathrm{P}=0.04$ ). $\mathrm{FI}$ discriminated between cases and non-cases of PE (IDI 0.041, P=0.04).

Conclusion:

First trimester placental vascularization indices (VI, FI and VFI) have the potential to predict $\mathrm{PE}$ in high-risk pregnancies, with $\mathrm{FI}$ remaining predictive in the second trimester.

\title{
Keywords
}

Pre-eclampsia, prediction, ultrasound, placental vascularization indices 


\section{Introduction}

Worldwide, hypertensive disorders of pregnancy are responsible for around $18 \%$ of maternal deaths each year $(62,000-77,000$ deaths/annum) $[1,2]$. Pre-eclampsia (PE) is a major cause of maternal and perinatal morbidity and mortality affecting approximately $2 \%$ of all pregnant women [3]. Women with type 1 and 2 diabetes mellitus (DM), a body mass index $(\mathrm{BMI})>35 \mathrm{~kg} / \mathrm{m}^{2}$, essential hypertension, a previous history of $\mathrm{PE}$, thrombophilia or autoimmune disease are at increased risk of adverse pregnancy outcomes, including PE [4].

The clinical significance of PE has resulted in it being the focus of research designed to improve our understanding of its aetiology and to develop better models of prediction. Predictive models have included maternal characteristics, assessment of previous obstetric history and inclusion of biophysical parameters such as maternal blood pressure, BMI and measurement of uterine artery Doppler. More recently, there has been increasing interest in 3-Dimensional Power Doppler (3DPD) acquisition of placental volume and placental vascularization indices (PVIs) and whether these might add to the predictive ability of established clinical and maternal serum and urine biomarkers [5-12].

Given that PE is in part attributed to a failure of placentation and remodelling of the maternal vasculature [13]; 3DPD evaluation of the placenta has the unique potential to offer clinicians a non-invasive means of assessing placental volume and PVIs [14]. The principle underlying measurement of colour flow Doppler is Doppler shift; defined as the difference between the frequency of received echoes from moving blood red cells and wave frequency transmitted by the transducer [15]. In contrast to frequency dependent colour flow Doppler, 
power Doppler ultrasound uses the amplitude component of signals received from the region of interest to represent the number of moving cells [16]. Subsequently, power Doppler is sensitive to low flow, is less angle dependent and not susceptible to aliasing [17].

A number of studies across general obstetric cohorts have shown significantly lower first trimester PVIs in women who subsequently develop PE [18], however little is known about the performance of PVIs for prediction of PE in high-risk women. The aim of this study was to assess the ability of PVIs measured in the first and second trimester to predict PE in a carefully characterised high-risk population. An additional aim was to evaluate the added clinical utility of PVIs for prediction of PE to that of established risk factors in high-risk women.

\section{Materials and methods}

The study population comprised high-risk women recruited to the PREDICT study (Prediction of PE in high-risk women) from a tertiary maternity unit in Northern Ireland ( $\mathrm{NI}$ ) between December 2014 and August 2016. The PREDICT study evaluated the clinical utility of whole volume derived 3DPD PVIs and serum biomarkers to predict PE in high-risk women in the first and second trimester of pregnancy. Written informed consent was obtained from all women. The Office for Research Ethics Committees NI (ORECNI) provided ethical approval (14/NI/1068). 
Eligible women aged $\geq 18$ years with a singleton pregnancy were recruited to one of four high-risk groups at 11+0-13+6 weeks gestation: (1) diabetes; pre-existing type 1 and type 2 diabetes (2) obesity; booking $\mathrm{BMI}>35 \mathrm{~kg} / \mathrm{m}^{2}$ (3) hypertension; essential hypertension, a previous obstetric history of PE, intrauterine growth restriction (IUGR) or renal disease (4) autoimmune; known thrombophilia or autoimmune disease.

The primary outcome was $\mathrm{PE}$, defined as hypertension after 20 weeks gestation and the coexistence of one or more of the following new-onset conditions: (1) proteinuria (2) maternal organ dysfunction or (3) uteroplacental dysfunction (i.e.) fetal growth restriction, in accordance with the International Society for the Study of Hypertension in Pregnancy (ISSHP) guidelines [19]. The diagnosis of PE was independently confirmed by three clinicians.

All participants attended for two study visits at 11+0-13+6 (visit 1) and 19+0-21+6 weeks gestation (visit 2). Scans were performed by one trained operator blinded to outcomes using a Voluson E8 ultrasound machine (GE Healthcare, MDI Medical (NI) Ltd) equipped with a 3D/4D convex transducer (2-8 MHz). Initial machine settings were based on those reported by Odibo et al. in an unselected obstetric population [20]. Additional work was undertaken to establish optimal machine settings in order to improve image quality, particularly in women with higher body mass indexes. Machine settings were subsequently optimised and maintained for all scans to help standardize the imaging technique (3DPD : depth $10.1 \mathrm{~cm}$, zoom 1.1, frame rate $9 \mathrm{~Hz}$, harmonics: high, power 97\%, frequency: low, pulse repetition frequency (PRF): $0.9 \mathrm{~Hz}$, wall motion filter (WMF): low, volume angle $85^{\circ}$, quality - high 1 , Compound Resolution Image (CRI): I, Speckle Reduction image (SRI): III. Transabdominal ultrasound was performed to obtain measurements of placental volume and PVIs: 
(Vascularization Index (VI): ratio of voxels to all voxels within the placenta (\%) [number of vessels], Flow Index [FI]: mean power Doppler signal intensity from all colour voxels (unitless) [intensity of flow] and Vascularization Flow Index (VFI): ratio of blood flow and vascularization) using a 3DPD whole volume placental imaging technique) [21]. A longitudinal view of the placental mass was obtained using 2D greyscale imaging. Depending on the size and location of the placenta, a slight lateral inclination of the transducer was used to acquire the images. The duration of image acquisition was between 10-15 seconds in the first trimester and between $30-40$ seconds in the second trimester. Using VOCAL software (Virtual Organ Computer-aided AnaLysis), the largest image of the placenta was located and positioned within the image acquisition box (box A) (figure 1). The region of interest was then adjusted before proceeding to off-line volume analysis. A manual tracing method of the placental border via six $30^{\circ}$ rotations was employed. Placental volumes were obtained twice for each participant to obtain optimal images and mean placental volume is reported throughout the analysis.

\section{Statistical analysis}

Preliminary comparison of baseline maternal characteristics in women who developed PE and those who did not was performed using independent sample $t$ tests and $\chi^{2}$ tests. Mean values (standard deviation, SD) of PV, VI, FI and VFI are reported for cases and non-cases of PE.

Logistic regression models using PE as the primary outcome were determined for each PVI in each high-risk group. To facilitate comparison of placental parameters in regression models, PVIs were standardized to have a mean of 0 and a standard deviation (SD) of 1 and 
results presented as standardized odds ratios. Covariates included: study group, age, BMI, smoking status, aspirin use (at visit 1 and visit 2), parity, material deprivation of area of residence and mean arterial pressure (MAP) (at visit 1 and visit 2). The area under the receiver operating characteristic (ROC) curve was used to assess the ability of each PVI to predict PE in high-risk women. Logistic regression analysis provided predicted probabilities of PE for a base model containing established risk factors and for models obtained by the addition of each PVI to the base model. These predicted probabilities were used to derive ROC curves, and the increase in the area under these curves was assessed for significance [22].

To quantify the added value of PVIs to that of established clinical risk factors for prediction of $\mathrm{PE}$, Integrated Discrimination Improvement (IDI) and category-free Net Reclassification Improvement (NRI) indices were calculated [23]. These incorporated predicted probabilities of development of PE for each woman derived from logistic regression models [24]. These indices offer additional information regarding the incremental yield of a new biomarker over the area under the ROC curve. The NRI was calculated on a continuous, uncategorised basis [23]. Defining PE as the event, it is described as the sum of $\mathrm{NRI}_{\text {(events) }}$ and $\mathrm{NRI}_{\text {(non-events) }}$ where $\mathrm{NRI}$ represents the proportion of women reclassified to a more appropriate risk on addition of the PVI to the logistic regression [24]. In women who developed PE, if the addition of the PVI results in more individuals being reclassified to a higher risk, then the $\mathrm{NRI}_{\text {(events) }}$ is positive. For women who did not develop PE, if more women are assigned as lower risk, then the $\mathrm{NRI}_{\text {(non-events) }}$ is positive. IDI was defined as the average increase in predicted risk of PE in women with PE added to the average decrease in predicted risk in women without PE [24]. 
A 20\% incidence of PE was assumed in the high-risk groups [25-27]. With an assumed interpatient SD in VFI of 5.2 [20], a sample size of 200 women in the high-risk groups was sufficient to give $90 \%$ power to detect a difference of 3.0 in mean VFI between women who did not develop PE (expected size 160) and women who did (expected size 40). Statistical analysis was performed using SPSS version 21 (IBM Corp., Armonk, NY), Stata release 14 (StataCorp, College Station, TX) and the Hmisc package in R version 3.1.3 (R Core Team, Vienna, Austria).

\section{Results}

A total of 202 high-risk women were enrolled in the PREDICT study. Analysis of placental parameters by primary outcome (PE) in high-risk women was performed at two time points; visit 1 at $11+0-13+6$ weeks $(n=194)$ and visit 2 at $19+0-21+6$ weeks gestation $(n=195)$. One woman had no PVIs stored for visit 1 . The overall rate of PE was $12 \%(n=26)$.

Baseline maternal characteristics are shown in table 1. No statistically significant differences in parity, age, ethnicity, BMI, gestational age at booking, smoking status, full time education, social deprivation, pregnancy intention or attendance at pre-pregnancy counselling or study grouping were noted between women who developed PE and those who did not. Table 2 compares mean placental volume and PVIs in women with PE and those without PE. In the first trimester, all PVIs were significantly lower in the PE group. There was no significant difference in mean placental volume between the two groups. At visit 2, mean FI was lower in women with PE. There was no significant difference in mean VI and VFI between the two groups. Similar to visit 1, mean placental volume in the second trimester was non- 
significantly lower in women with PE. Additional analysis was performed to investigate the change in placental measurements between visit 1 and visit 2 for women with and without PE; however this analysis did not yield any significant results.

Reliability analysis was conducted for a subset of images chosen at random $(n=30)$. Images for the same patients were evaluated in the first and second trimester. Analysis of images evaluated twice by the same operator demonstrated good repeatability $(r)$ for VI, FI and VFI in the first and second trimester. At $11+0-13+6$ weeks gestation, intra class correlationcoefficients (ICC) for VI, FI and VFI were $0.95,0.96$ and 0.94 , respectively. Co-efficient of variation (CV) measurement ranged from 5.0-11.4\%. In the second trimester, ICC for $\mathrm{VI}, \mathrm{FI}$ and VFI were $0.97,0.68$ and 0.95 , respectively. Co-efficient of variation (CV) measurements were higher (range: 8.1-12.9\%). Between image variation demonstrated fair repeatability in the first trimester; ICC was $>0.8$ for all placental vascularization indices (PVIs) with CV measurements ranging from 4.3-18.6\%. Between 19+0-21+6 weeks gestation, $r$ and CV measurements (13.6-26.2\%) were less reliable and ICCs were lower (0.40-0.79).

The relationship between placental volume, PVIs and risk of PE was explored using logistic regression models both unadjusted and after controlling for clinical risk factors: study group, age, BMI, smoking status, aspirin use, parity, material deprivation of area of residence and MAP (table 3). In the first trimester, the associations between $\mathrm{VI}, \mathrm{FI}$ and $\mathrm{VFI}$ and risk of developing PE remained significant after adjustment. In particular, a 1 SD increase in VFI was associated with a $68 \%$ reduction in the odds of PE in high-risk women (OR $0.32,95 \% 0.14$ $0.72, \mathrm{P}=0.01$ ). In the second trimester, only $\mathrm{FI}$ remained significant following adjustment; a 1 
SD increase in $\mathrm{FI}$ was associated with a $47 \%$ reduction in the odds of developing PE (OR 0.53 , $95 \% \mathrm{Cl}$ 0.29-0.97, $\mathrm{P}=0.04)$.

Receiver operating characteristic (ROC) analysis of PVIs was used to assess the predictive value of PVIs and baseline maternal characteristics (table 4). In the first trimester, the area under the ROC curve for baseline maternal characteristics (0.74) showed non-significant improvements with the addition of $\mathrm{VI}, \mathrm{FI}$ and VFI (areas $0.79,0.78,0.81$, respectively). At visit 2, a non-improvement in area under the ROC curve was observed for addition of FI to a model incorporating established maternal characteristics. The corresponding analyses for VI and VFI showed little change in the area under the ROC curve. At an $80 \%$ specificity (equivalent to a $20 \%$ false positive rate), the first trimester model containing baseline maternal characteristics had $44 \%$ sensitivity for prediction of PE. Addition of VI, $\mathrm{FI}$ and VFI improved sensitivity of the model to $52 \%(P=0.73), 48 \% \quad(P=1.00)$ and $66 \% \quad(P=0.23)$, respectively. The second trimester model incorporating only maternal characteristics had $65 \%$ sensitivity for prediction of PE (80\% specificity). Only addition of $\mathrm{FI}$ improved performance of this model (70\% sensitivity) for prediction of PE.

To determine the ability of PVIs to improve prediction of PE in addition to maternal baseline characteristics, NRI and IDI statistics were calculated (table 4). In the first trimester, both the $\mathrm{NRI}$ and IDI showed that the addition of $\mathrm{VI}$ and VFI to established clinical risk factors significantly increased correct classification and discrimination of cases and non-cases of PE. In the second trimester, the IDI statistic demonstrated that addition of FI to established risk factors significantly improved discrimination between cases and non-cases. 


\section{Discussion}

The aim of the PREDICT study was to examine novel predictive markers of PE, a highly significant and clinically relevant global health problem. To our knowledge, this is the first study which prospectively examines the clinical utility of PVIs obtained by whole volume 3DPD placental scanning to predict PE in carefully defined groups of high-risk women.

We have shown significantly lower first trimester PVIs in high-risk women who subsequently develop PE. This supports previous findings in unselected study populations [9-11,18]. All PVIs remained significant predictors of PE in logistic regression models controlling for baseline characteristics in the first trimester. Higher values of PVIs were associated with a reduction in odds of developing PE in the first trimester. Of importance, NRI and IDI analyses confirmed the added clinical utility of $\mathrm{VI}$ and $\mathrm{VFI}$, in addition to models incorporating baseline maternal characteristics at $11+0-13+6$ weeks.

Little is known about the performance of PVIs for prediction of PE in the second trimester of pregnancy. FI and VFI were significantly lower in women with PE in the second trimester, however only $\mathrm{FI}$ remained a significant predictor of $\mathrm{PE}$ in adjusted logistic regression models. Examining the added clinical utility of $\mathrm{Fl}$ confirmed significant improvement in discrimination of cases (IDI) but no improvement in the reclassification of cases (NRI). Difficulty imaging the placenta in the second trimester may have impacted the performance of PVIs. Despite adjustments to optimise sector width, it was not always possible to scan large placental masses in their entirety. This technical challenge was previously reported by Lai et al. who thought it may have influenced acquisition of standardized measurements [28]. 
Further research is required to evaluate performance of 3DPD imaging in specific high-risk obstetric subgroups. To date, limited research investigating the role of PVIs to aid management of pregnancies complicated by DM exists $[29,30]$. Previously reported decreases in VI and VFI in diabetic placentas $[29,30]$ may be as a result of down-regulated angiogenesis, diminished number of arterioles and hypertrophy of vessel walls, while reductions in $\mathrm{Fl}$ are thought to be the a result of narrowed vascular diameter [31]. These findings remain debated with, Rizzo et al. noting higher first trimester PVIs in women with type I DM ( $n=32)$ and highest PVIS observed in women with poorest glycaemic control (HbA1c $\geq 7 \%)$ [32]. A potential explanation may be attributed to the gestation at which PVIs in women with diabetes were acquired. In the first trimester, hyperglycaemia triggers vasculogenesis but vasculopathy occurs later [31]; therefore reduction in placental blood flow (FI) and alterations in vascularization indices typically noted in later pregnancy are not yet apparent $[31,33]$. Variation in the performance of PVIs has also been demonstrated in pregnancies complicated by chronic hypertension $(\mathrm{CH})$, gestational hypertension and PE $(n=226)[34,35]$. Compared with controls, VI was higher in pregnancies complicated by $\mathrm{CH}$ and FI was significantly lower in all hypertensive groups [34]. The authors suggested that the increase in VI noted in women with $\mathrm{CH}$ may represent a placental response - elevated vascularization rate - to increased maternal blood pressure and hypothesised that the reduction in $\mathrm{Fl}$ seen throughout the groups reflected impaired perfusion in the placenta [34]. Within obese cohorts, it has been suggested that flow indices are relatively unreliable for prediction of PE [9], and that future research should focus only on the role of vascularization indices (VI and VFI) [9,36]. Flow indices are depth dependent and, in the obese population, there is an increased distance from the placenta to the abdominal surface 
which may influence performance of FI. In addition, excess adipose tissue increases attenuation of ultrasound signal, resulting in impaired absorption by placental tissue [37].

The PREDICT study has a number of strengths including adherence to strict inclusion and exclusion criteria, ensuring that pregnancies were carefully characterised prior to enrolment. There was a low attrition rate and sample size was achieved. PVI measurements were obtained by a single operator, and the primary outcome (PE) was carefully defined [19] and independently verified by three clinicians. The comprehensive and detailed statistical analysis strategy allowed construction of screening models involving potential predictor variables for PE. There are a number of limitations; in particular, the lower than anticipated rate of PE (12\%) which reduced the power of the study. Sample size was calculated on the assumption of a $20 \%$ incidence of PE [25-27]. The reduced incidence of PE may have been due to the influence of prevention strategies, such as aspirin use, or availability of dedicated specialist care. In addition, the numbers within each of the subgroups were relatively small, as some of these women, such as those with diabetes, were difficult to recruit. Given the small numbers of women with PE in the overall cohort, it was not feasible to sub-divide the group further in order to evaluate performance of PVIs in cases of early-onset PE (before 34 weeks gestation) and late-onset PE (after 37 weeks gestation). It should also be acknowledged that the final logistic regression models were adjusted for a number of covariates; this may confer a risk of over adjustment in the model.

There remains ongoing controversy regarding application of 3DPD imaging in clinical practice [38]. In contrast to frequency dependent colour flow Doppler, power Doppler ultrasound uses the amplitude component of signals received from the region of interest to 
represent the number of moving cells [16]. Subsequently, power Doppler is sensitive to low flow, is less angle dependent and not susceptible to aliasing [17]. Raine-Fenning et al. have demonstrated the influence of volume flow, attenuation, vessel number and erythrocyte density on performance of PVIs [39]. In addition, a number of studies have highlighted the impact of machine settings on performance of PVIs; in particular the effect of, WMF, PRF and gain [40-42]. In the PREDICT study, WMF and PRF were standardized and maintained for all scans, however gain was individualised in order to optimize images and account for inter-subject variability in attenuation. If 3DPD imaging was to be introduced for prediction of PE within a clinical setting, strict adherence to pre-defined machine settings would be imperative.

Data from the PREDICT study show the ability of PVIs to predict PE in high-risk pregnancies, particularly in the first trimester. The results are of clinical significance and have the potential to identify at risk women, over and above established risk factors, in early pregnancy at a time when they can be targeted for preventive strategies. Further research is required to evaluate performance of PVIs within larger specific high-risk cohorts and to investigate the clinical utility of this technique in the second trimester of pregnancy.

\section{Acknowledgements}

We wish to thank all the women who took part in the PREDICT study for their involvement. 


\section{References}

[1] K.S. Khan, D. Wojdyla, L. Say, A.M. Gülmezoglu, P.F.A. Van Look, WHO analysis of causes of maternal death: a systematic review, Lancet 367 (2006) 1066-74.

[2] E. Abalos, C. Cuesta, A.L. Grosso, D. Chou, L. Say, Global and regional estimates of preeclampsia and eclampsia: a systematic review, Eur. J. Obstet. Gynecol. Reprod. Biol. 170 (2013) 1-7.

[3] E. Abalos, C. Cuesta, G. Carroli, Z. Qureshi, M. Widmer, J.P. Vogel, J.P. Souza, Preeclampsia, eclampsia and adverse maternal and perinatal outcomes: a secondary analysis of the World Health Organization Multicountry Survey on Maternal and Newborn Health, Br. J. Obstet. Gynaecol. 121 (2014) 14-24.

[4] National Collaborating Centre for Women's and Children's health, Hypertension in pregnancy: the management of hypertensive disorders during pregnancy, London, 2010.

[5] D. Wright, R. Akolekar, A. Syngelaki, L.C.Y. Poon, K.H. Nicolaides, A competing risks model in early screening for preeclampsia., Fetal Diagn. Ther. 32 (2012) 171-8.

[6] L. Poon, K. Nicolaides, First-trimester maternal factors and biomarker screening for preeclampsia, Prenat. Diagn. 34 (2014) 618-627.

[7] J. Cnossen, R. Morries, G. ter Reit, B. Mol, J. van der Post, A. Coomarasamy, A. Zwinderman, S. Robson, P. Bindels, J. Kleijnen, K. Khan, Use of uterine artery Doppler ultrasonography to predict pre-eclampsia and intrauterine growth restriction: a systematic review and bivariable meta-analysis, Can. Med. Assoc. J. 178 (2008) 1-11.

[8] L.C.Y. Poon, N.A. Kametas, T. Chelemen, A. Leal, K.H. Nicolaides, Maternal risk factors for hypertensive disorders in pregnancy: a multivariate approach, J. Hum. Hypertens. 24 (2010) 104-10. 
[9] E. Hafner, M. Metzenbauer, I. Stümpflen, T. Waldhör, K. Philipp, First trimester placental and myometrial blood perfusion measured by 3D power Doppler in normal and unfavourable outcome pregnancies, Placenta. 31 (2010) 756-63.

[10] S. Demers, M. Girard, S. Roberge, A. Tétu, Y. Giguère, J.-C. Forest, E. Bujold, FirstTrimester Placental and Myometrial Blood Perfusion Measured by Three-Dimensional Power Doppler in Preeclampsia, Amer J Perinatol. 32 (2015) 920-926.

[11] W. Plasencia, E. González-Dávila, A. González Lorenzo, M. Armas-González, E. Padrón, N.L. González-González, First trimester placental volume and vascular indices in pregnancies complicated by preeclampsia, Prenat. Diagn. 35 (2015) 1247-1254.

[12] K. Hannaford, M. Tuuli, K. Goetzinger, L. Odibo, A. Cahill, G. Macones, A. Odibo, FirstTrimester 3-Dimensional Power Doppler Placental Vascularization Indices From The Whole Placenta Versus the Placental Bed to Predict Preeclampsia. Does PregnancyAssociated Plasma Protein A or Uterine Artery Doppler Sonography Help?, J. Ultrasound Med. 24 (2015) 965-70.

[13] C. Redman, I. Sargent, Latest advances in understanding preeclampsia, Science. 308 (2005) 1592-1594.

[14] S. Natsis, P. Antsaklis, A. Antsaklis, A. Kurjak, Three-dimensional Evaluation of the Placenta: Review of the Literature, Donald Sch. J. Ultrasound Obstet. Gynecol. 7 (2013) 73-79.

[15] C. Deane, Doppler ultrasound: principles and practice, in: K.H. Nicolaides, G. Rizzo, K. Hecher, R. Ximenes (Eds.), Doppler Obstet., The Fetal Medicine Foundation, London, 2002: pp. 4-24. 
[16] H. Pairleitner, H. Steiner, G. Hasenoehrl, A. Staudach, Three-dimensional power Doppler sonography: Imaging and quantifying blood flow and vascularization, Ultrasound Obstet. Gynecol. 14 (1999) 139-143.

[17] J.M. Rubin, R.S. Adler, J.B. Fowlkes, S. Spratt, J.E. Pallister, J.F. Chen, P.L. Carson, Fractional moving blood volume: estimation with power Doppler US, Radiology. 197 (1995) 183-190.

[18] K.A. Eastwood, C. Patterson, A.J. Hunter, D.R. McCance, I.S. Young, V.A. Holmes, Evaluation of the predictive value of placental vascularisation indices derived from 3Dimensional power Doppler whole placental volume scanning for prediction of preeclampsia: A systematic review and meta-analysis, Placenta. 51 (2017) 89-97.

[19] A.L. Tranquilli, G. Dekker, L. Magee, J. Roberts, B.M. Sibai, W. Steyn, G.G Zeeman, M.A. Brown, The classification, diagnosis and management of the hypertensive disorders of pregnancy: A revised statement from the ISSHP, Pregnancy Hypertens. 4 (2014) 97-104.

[20] A. Odibo, K. Goetzinger, K. Huster, J. Christiansen, L. Odibo, M. Tuuli, Placental volume and vascular flow assessed by 3D power Doppler and adverse pregnancy outcomes, Placenta. 32 (2011) 230-4.

[21] J. Alcázar, Three-dimensional power Doppler derived vascular indices: what are we measuring and how are we doing it?, Ultrasound Obstet. Gynecol. 32 (2008) 485-7.

[22] E.R. Delong, D.M. Delong, D.L. Clarke-pearson, N. Carolina, Comparing the Areas under Two or More Correlated Receiver Operating Characteristic Curves : A Nonparametric Approach, Biometrics. 44 (1988) 837-845. 
[23] M.J. Pencina, R.B. D’Agostino Sr, E.W. Steyerberg, Extensions of net reclassification improvement calculations to measure usefulness of new biomarkers, Stat. Med. 30 (2011) 11-21.

[24] J.W. Pickering, Z.H. Endre, New metrics for assessing diagnostic potential of candidate biomarkers, Clin. J. Am. Soc. Nephrol. 7 (2012) 1355-1364.

[25] I. Herraiz, D. Escribano, P.I. Gómez-Arriaga, J.M. Hernández-García, M.A. Herraiz, A. Galindo, Predictive value of sequential models of uterine artery Doppler in pregnancies at high risk for pre-eclampsia, Ultrasound Obstet. Gynecol. 40 (2012) 6874.

[26] S. Bhattacharya, D.M. Campbell, W.A. Liston, S. Bhattacharya, Effect of Body Mass Index on pregnancy outcomes in nulliparous women delivering singleton babies, BMC Public Health. 7 (2007) 1-8.

[27] E. Hafner, M. Metzenbauer, I. Stümpflen, T. Waldhör, Measurement of placental bed vascularization in the first trimester, using 3D-power-Doppler, for the detection of pregnancies at-risk for fetal and maternal complications, Placenta. 34 (2013) 892-8.

[28] P.K. Lai, Y.A. Wang, A.W. Welsh, Reproducibility of regional placental vascularity/perfusion measurement using 3D power Doppler, Ultrasound Obstet. Gynecol. 36 (2010) 202-9.

[29] A. Surányi, Z. Kozinszky, A. Molnár, T. Nyári, T. Bitó, A. Pál, Placental threedimensional power Doppler indices in mid-pregnancy and late pregnancy complicated by gestational diabetes mellitus, Prenat. Diagn. 33 (2013) 952-8.

[30] M. Moran, C. Mulcahy, L. Daly, G. Zombori, P. Downey, F.M. McAuliffe, Novel placental ultrasound assessment: Potential role in pre-gestational diabetic pregnancy, Placenta. 35 (2014) 639-644. 
[31] U. Hiden, J. Froehlich, G. Desoye, Diabetes and the Placenta, in: H. Kay, D. Nelson, Y. Wang (Eds.), Placenta From Development to Disease, Wiley-Blackwell, Oxford, 2011: $228-230$.

[32] G. Rizzo, A. Capponi, M.E. Pietrolucci, E. Aiello, D. Arduini, First trimester placental volume and three dimensional power doppler ultrasonography in type I diabetic pregnancies, Prenat. Diagn. 32 (2012) 480-4.

[33] L. Leach, Placental vascular dysfunction in diabetic pregnancies: intimations of fetal cardiovascular disease?, Microcirculation. 18 (2011) 263-269.

[34] A. Surányi, Á. Altorjay, L. Kaiser, T. Nyári, G. Németh, Evaluation of placental vascularization by three-dimensional ultrasound examination in second and third trimester of pregnancies complicated by chronic hypertension, gestational hypertension and pre-eclampsia, Pregnancy Hypertens. An Int. J. Women's Cardiovasc. Heal. 8 (2017) 51-59.

[35] C.Y. Chen, K.G. Wang, C.P. Chen, Alteration of vascularization in preeclamptic placentas measured by three-dimensional power Doppler ultrasound, J. Matern. Fetal. Neonatal Med. 26 (2013) 1616-22.

[36] E. de Almeida Pimenta, C. Silva de Paula, J. Duarte Bonini Campos, K. Fox, R. Francisco, R. Ruano, M. Zugaib, Three-Dimensional Sonographic Assessment of Placental Volume and Vascularization in Pregnancies Complicated by Hypertensive Disorders, J. Ultrasound Med. 33 (2014) 483-491.

[37] D. Paladini, Sonography in obese and overweight pregnant women: Clinical, medicolegal and technical issues, Ultrasound Obstet. Gynecol. 33 (2009) 720-729. 
[38] A.W. Welsh, S.L. Collins, G.N. Stevenson, J.A. Noble, L. Impey, Inapplicability of fractional moving blood volume technique to standardize Virtual Organ Computeraided AnaLysis indices for quantified three-dimensional power Doppler, Ultrasound Obstet. Gynecol. 40 (2012) 688-692.

[39] N.J. Raine-Fenning, N.M. Nordin, K.V. Ramnarine, B.K. Campbell, J.S. Clewes, A. Perkins, I.R. Johnson, Determining the relationship between three-dimensional power Doppler data and true blood flow characteristics: An in-vitro flow phantom experiment, Ultrasound Obstet. Gynecol. 32 (2008) 540-550.

[40] W.P. Martins, N.J. Raine-Fenning, R.A. Ferriani, C.O. Nastri, Quantitative threedimensional power Doppler angiography: A flow-free phantom experiment to evaluate the relationship between color gain, depth and signal artifact, Ultrasound Obstet. Gynecol. 35 (2010) 361-368.

[41] N.J. Raine-Fenning, N.M. Nordin, K. V. Ramnarine, B.K. Campbell, J.S. Clewes, A. Perkins, I.R. Johnson, Evaluation of the effect of machine settings on quantitative three-dimensional power Doppler angiography: An in-vitro flow phantom experiment, Ultrasound Obstet. Gynecol. 32 (2008) 551-559.

[42] M.R. Martins, W.P. Martins, C.A.M. Soares, A.H. Miyague, M.J. Kudla, T.Z. Pavan, Understanding the Influence of Flow Velocity, Wall Motion Filter, Pulse Repetition Frequency, and Aliasing on Power Doppler Image Quantification, J. Ultrasound Med. 37 (2018) 255-261. 


\section{Funding statement}

This study was funded by a Health and Social Care Research and Development Award from the Public Health Agency, Northern Ireland (EAT/4904/13). The funding organisation had no role in the study design, data collection, analysis and interpretation of data, preparation of the manuscript or decision to submit the article for publication. 


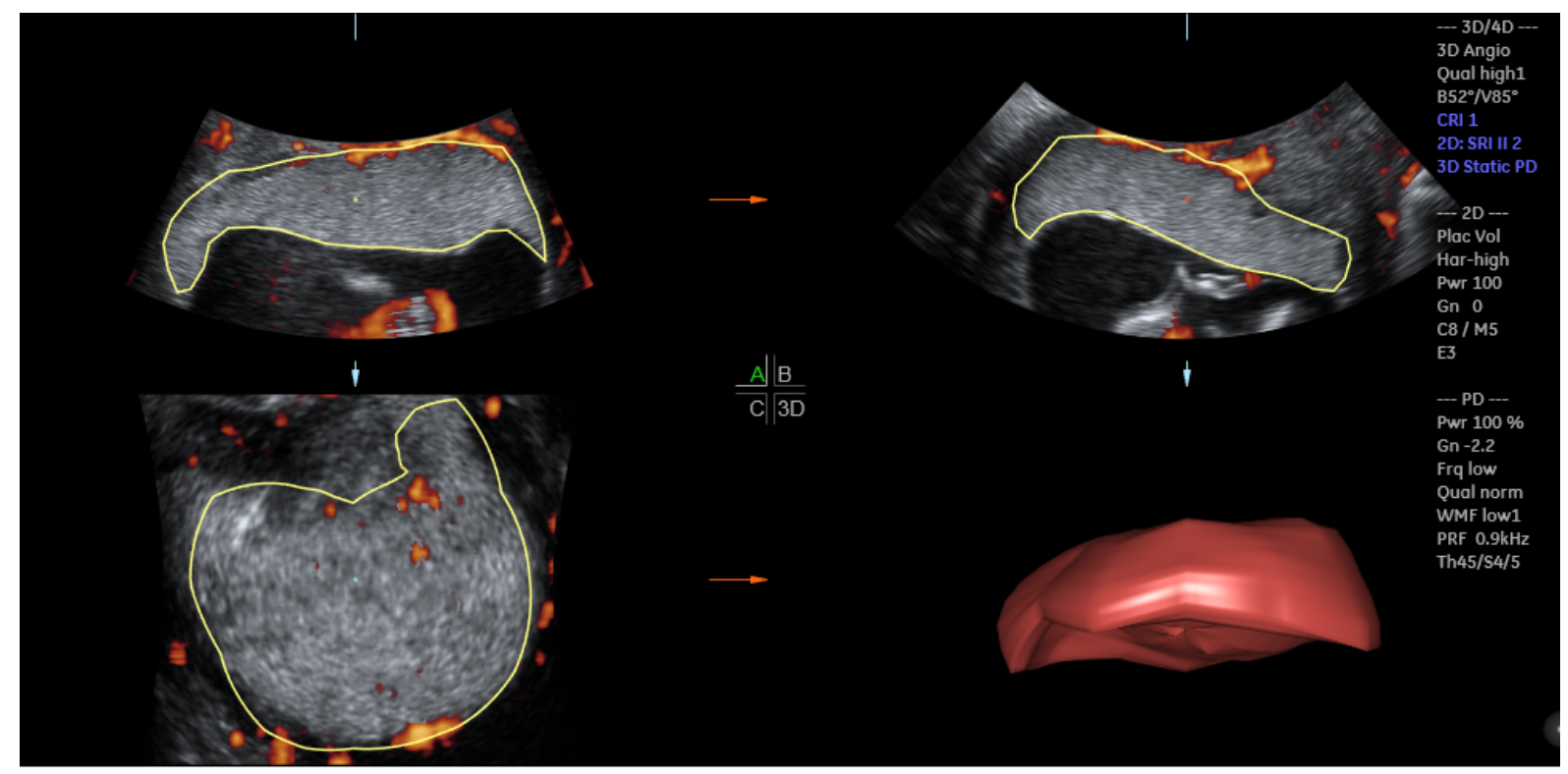

(A) Placental images - 2D grey scale and 3D placental volume

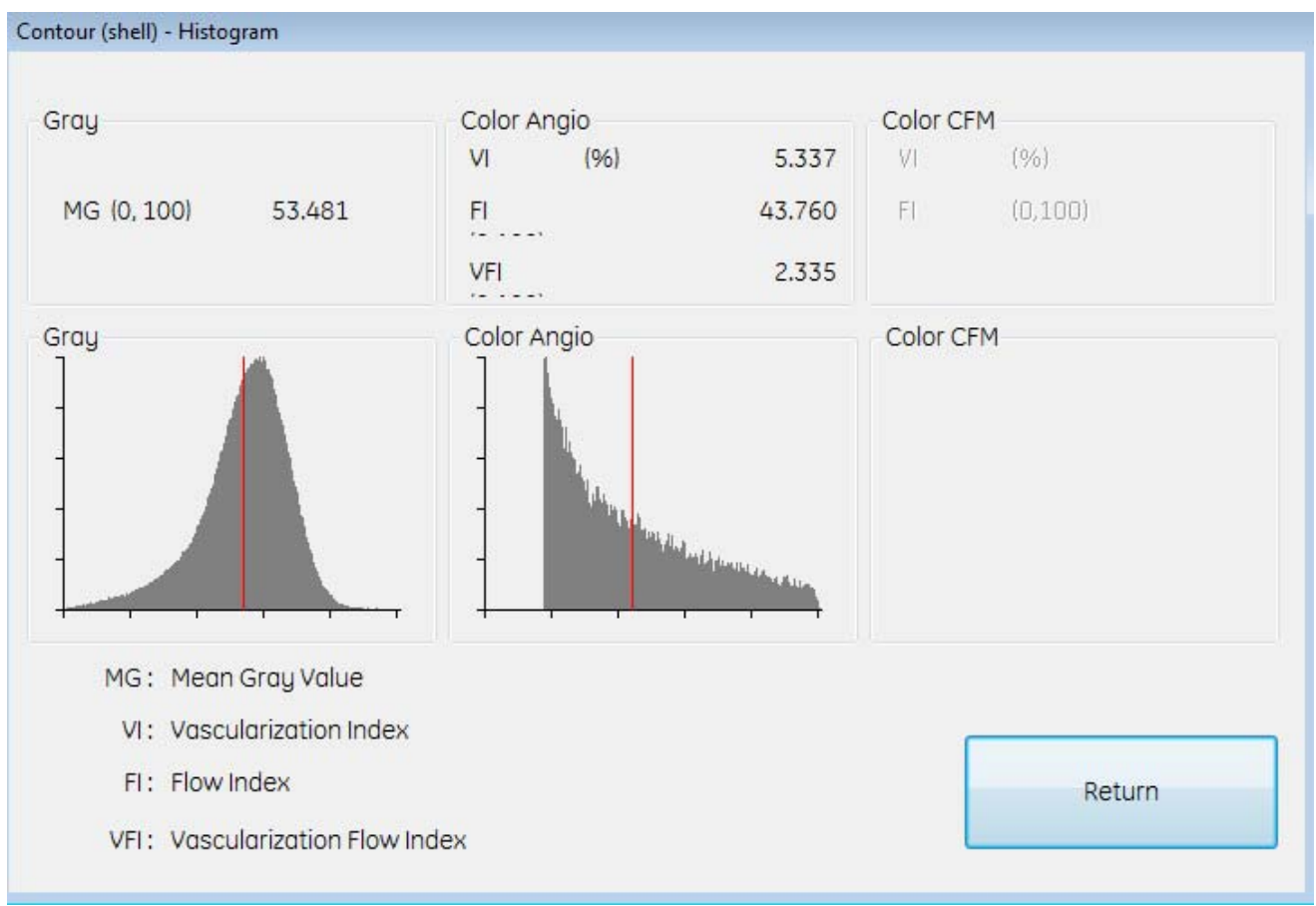

(B) Volume histogram demonstrating placental vascularization indices

Figure 1: 3-Dimensional Power Doppler imaging of the placenta using Virtual Organ Computer-aided AnaLysis technique (VOCAL). Acquisition of placental vascularization images at $12+2$ weeks gestation. 
(A) The placental was first delineated in 2D grey scale (reference image A). Using VOCAL, the placenta was rotated through $30^{\circ}$ rotations (6 rotations) to attain the $3 \mathrm{D}$ placental volume

(B) Placental vascularization indices (vascularization index, flow index, vascularization flow index) were generated from the volume histogram 


\begin{tabular}{|c|c|c|c|}
\hline Baseline characteristics (V1) & No PE (n=172) & $\operatorname{PE}(n=23)$ & $\mathbf{P}$ \\
\hline Maternal age (y); mean (SD) & $31.8(5.4)$ & $32.9(5.2)$ & 0.39 \\
\hline BMI $\left(\mathrm{kg} / \mathrm{m}^{2}\right)$; mean (SD) & $32.7(9.1)$ & $33.7(9.3)$ & 0.62 \\
\hline Gestational age (weeks); mean (SD) & $12.2(0.6)$ & $12.4(0.7)$ & 0.26 \\
\hline Full time education (y); mean (SD) & $16.0(3.3)$ & $16.3(2.8)$ & 0.65 \\
\hline Ethnicity (white) $(n, \%)$ & $163(95)$ & $20(87)$ & 0.15 \\
\hline Parous (parity $\geq 1)(n, \%)$ & $131(76)$ & $14(61)$ & 0.11 \\
\hline Smoker (n,\%) & $33(19)$ & $3(13)$ & 0.58 \\
\hline Most socially deprived fifth $(n, \%)$ & $66(38)$ & $13(57)$ & 0.10 \\
\hline Planned pregnancy $(n, \%)$ & $120(70)$ & $16(70)$ & 0.98 \\
\hline Received pre-pregnancy counselling $(n, \%)$ & $43(25)$ & $4(17)$ & 0.42 \\
\hline Spontaneous conception ( $n, \%)$ & $170(99)$ & $22(96)$ & 0.32 \\
\hline Pre-conception folic acid (n,\%) & $75(45)$ & $12(52)$ & 0.66 \\
\hline Stopped alcohol pre conception (n,\%) & $89(52)$ & $14(61)$ & 0.57 \\
\hline Aspirin at visit $1(n, \%)$ & $41(24)$ & $5(22)$ & 0.82 \\
\hline Mean systolic BP (mmHg); mean (SD) & $122.5(12.1)$ & $126.2(11.8)$ & 0.18 \\
\hline Mean diastolic BP (mmHg); mean (SD) & $78.7(10.6)$ & $82.5(9.9)$ & 0.10 \\
\hline Mean arterial pressure $(\mathrm{mmHg})$; mean (SD) & $93.3(10.6)$ & $97.1(9.7)$ & 0.11 \\
\hline Diabetes group $(n, \%)$ & $25(15)$ & $4(17)$ & \\
\hline Obesity group (n,\%) & $49(28)$ & $9(39)$ & 0.49 \\
\hline Hypertension group ( $n, \%)$ & $52(30)$ & $7(30)$ & \\
\hline Autoimmune group $(n, \%)$ & $46(27)$ & $3(13)$ & \\
\hline
\end{tabular}

Table 1: Maternal baseline characteristics by pre-eclampsia outcome 


\begin{tabular}{llll}
\hline Placental parameters & No PE (n=172+) & PE (n=23) & P \\
\hline Visit 1 (11+0-13+6 weeks) & $52.1(20.9)$ & $48.0(16.9)$ & 0.37 \\
Placental volume; mean (SD) & $14.7(7.6)$ & $10.0(6.2)$ & $0.005^{*}$ \\
Vascularization Index; mean (SD) & $42.9(10.4)$ & $37.7(9.1)$ & $0.03^{*}$ \\
Flow Index; mean (SD) & $6.6(4.0)$ & $3.8(2.5)$ & $<0.001^{*}$ \\
Vascularization Flow Index; mean (SD) & & & \\
& & & 0.55 \\
Visit 2 (19+0-21+6 weeks) & & $197.9(60.6)$ & 0.51 \\
Placental volume; mean (SD) & $208.8(84.9)$ & $39.6(9.1)$ & $0.01^{*}$ \\
Vascularization Index; mean (SD) & $21.4(9.9)$ & & \\
Flow Index; mean (SD) & $44.4(8.6)$ & & 0.05 \\
Vascularization Flow Index; mean (SD) & $9.1(3.5)$ & & \\
\hline
\end{tabular}

Table 2: Comparison of placental parameters in the first and second trimester for the prediction of preeclampsia

Placental volume $\left(\mathrm{cm}^{3}\right)$, Vascularization Index (\%)

† One woman had no results at visit 1

${ }^{*}$ Statistically significant results $(\mathrm{P}<0.05)$ 
Visit $1(11+0-13+6$ weeks) $(n=194)$

Placental volume $\left(\mathrm{cm}^{3}\right)$

Vascularization Index (\%)

Flow Index

Vascularization Flow Index

Visit 2 (19+0-21+6 weeks) ( $n=195)$

Placental volume $\left(\mathrm{cm}^{3}\right)$

Vascularization Index (\%)

Flow Index

Vascularization Flow Index
$0.80(0.49-1.30), 0.37$

$0.41(0.21-0.77), 0.006^{*}$

$0.61(0.39-0.95), 0.03^{*}$

$0.34(0.17-0.70), 0.003^{*}$

$0.87(0.55-1.37), 0.55$

$0.85(0.54-1.36), 0.51$

$0.58(0.37-0.90), 0.02^{*}$

$0.61(0.37-1.01), 0.05$
$0.71(0.42-1.22), 0.22$

$0.42(0.21-0.85), 0.02^{*}$

$0.54(0.30-0.98), 0.04^{*}$

$0.32(0.14-0.72), 0.006^{*}$

0.69 (0.39-1.23), 0.21

$0.87(0.53-1.43), 0.59$

$0.53(0.29-0.97), 0.04^{*}$

0.67 (0.39-1.15), 0.14

Table 3: Logistic regression models for the prediction of pre-eclampsia including placental parameters and covariates at visit $1(11+0-13+6$ weeks) and visit $2(19+0-21+6$ weeks)

† Standardised OR is the odds ratio associated with a 1 standard deviation change in the placental parameter ¥ Covariates included: final grouping, age, body mass index (BMI), smoking status, aspirin use, parity, material deprivation of area of residence and mean arterial blood pressure (MAP)

${ }^{*}$ Statistically significant results $(P<0.05)$ 


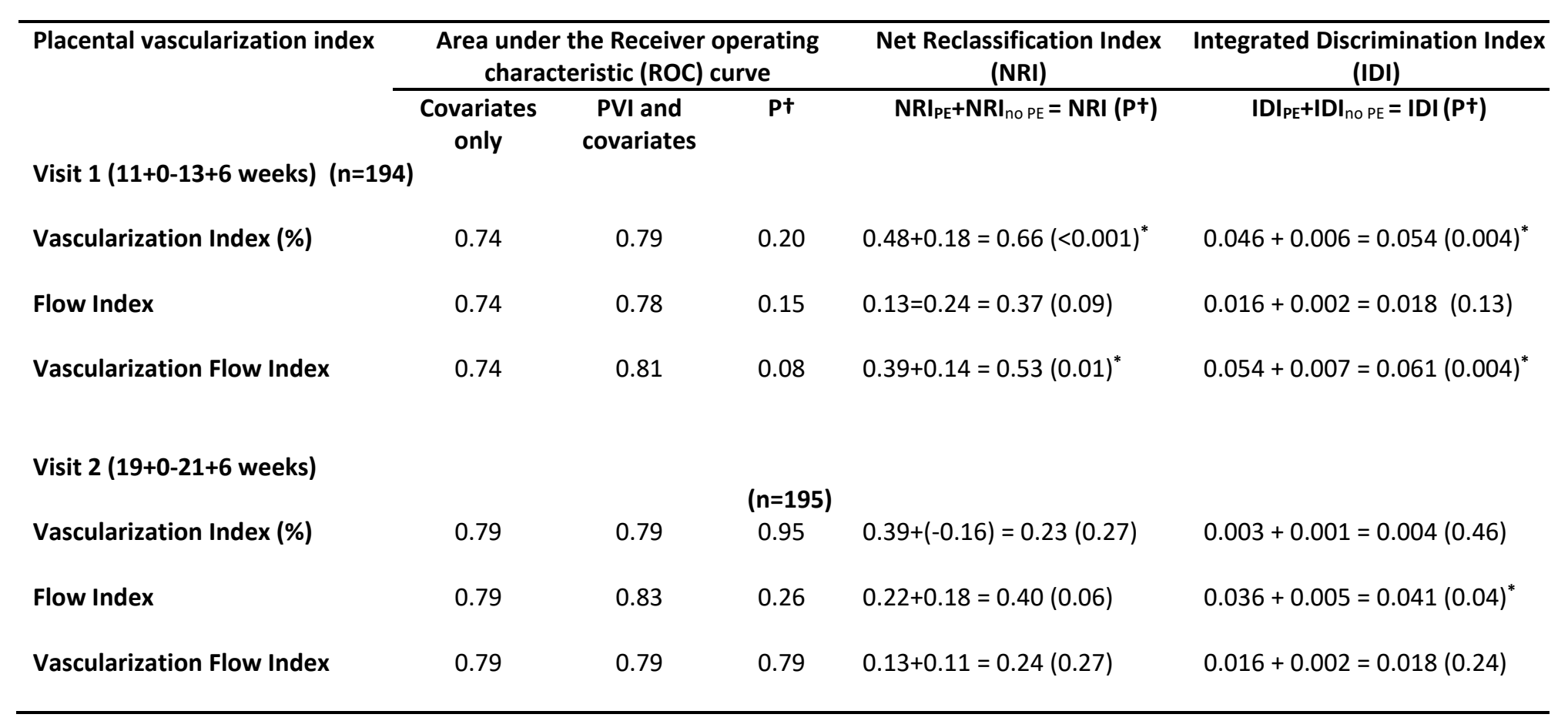

Table 4: Added clinical utility of placental vascularization indices to conventional clinical covariates for prediction of pre-eclampsia

PE: Pre-eclampsia

† Placental vascularization index and covariates relative to the covariates only

${ }^{*}$ Statistically significant result $(P<0.05)$ 


\begin{tabular}{|c|c|c|c|c|c|c|c|c|c|}
\hline \multirow{3}{*}{$\begin{array}{l}\text { Placental } \\
\text { parameter }\end{array}$} & \multicolumn{2}{|c|}{ Diabetes } & \multicolumn{2}{|c|}{ Obesity } & \multicolumn{2}{|c|}{ Hypertension } & \multicolumn{2}{|c|}{ Autoimmune } & \multirow[b]{3}{*}{$\mathrm{P}$} \\
\hline & \multicolumn{2}{|c|}{$(n=31)$} & \multicolumn{2}{|c|}{$(n=59)$} & \multicolumn{2}{|c|}{$(n=61)$} & \multicolumn{2}{|c|}{$(n=50)$} & \\
\hline & Mean (SD) & $95 \% \mathrm{Cl}$ & Mean (SD) & $95 \% \mathrm{Cl}$ & Mean (SD) & $95 \% \mathrm{Cl}$ & Mean (SD) & $95 \% \mathrm{Cl}$ & \\
\hline \multicolumn{10}{|c|}{ Visit 1 (11+0-13+6 weeks) } \\
\hline $\operatorname{PV}\left(\mathrm{cm}^{3}\right)$ & $50.7(17.0)$ & $44.5-56.9$ & $50.3(21.6)$ & $44.7-56.0$ & $53.0(20.9)$ & $47.6-58.3$ & $50.2(21.8)$ & $44.0-56.4$ & 0.88 \\
\hline VI (\%) & $13.4(6.7)$ & $11.0-15.9$ & $14.1(9.0)$ & $11.8-16.4$ & $14.6(7.8)$ & $12.6-16.6$ & $14.3(6.7)$ & $12.4-16.2$ & 0.91 \\
\hline FI & $42.1(9.4)$ & $38.7-45.6$ & $35.7(9.0)^{b}$ & $33.3-38.1$ & $45.0(9.6)$ & $42.5-47.5$ & $46.1(9.8)$ & $43.3-48.8$ & $<0.001^{a}$ \\
\hline \multicolumn{10}{|c|}{ Visit 2 (19+0-21+6 weeks) } \\
\hline & \multicolumn{2}{|c|}{$(n=29)$} & \multicolumn{2}{|c|}{$(n=58)$} & \multicolumn{2}{|c|}{$(n=60)$} & \multicolumn{2}{|c|}{$(n=50)$} & \\
\hline $\operatorname{PV}\left(\mathrm{cm}^{3}\right)$ & 211.9 (91.9) & 176.9-246.9 & $235.6(78.9)^{b}$ & 214.9-256.4 & 202.4 (71.9) & 183.9-221.0 & $174.7(82.6)^{b}$ & 151.2-198.2 & $0.002^{\mathrm{a}}$ \\
\hline VI (\%) & $18.0(7.6)$ & 15.1-20.9 & $23.8(12.2)$ & $20.6-27.0$ & $20.9(9.8)$ & $18.4-23.5$ & $20.0(8.3)$ & $17.6-22.3$ & 0.06 \\
\hline FI & $45.2(6.8)$ & $42.7-47.8$ & $39.4(8.6)^{b}$ & $37.1-41.7$ & $44.4(8.8)$ & $42.1-46.7$ & $48.0(7.9)$ & $45.8-50.3$ & $<0.001^{a}$ \\
\hline VFI & $8.1(3.6)$ & 6.7-9.7 & $8.9(3.6)$ & 7.9-9.8 & $8.9(3.7)$ & 8.0-9.8 & $9.3(3.3)$ & $8.4-10.3$ & 0.50 \\
\hline
\end{tabular}

Table S1: Comparison of placental parameters across study groups at visit 1 and visit 2 using ANOVA (One way Analysis Of Variance)

PV: Placental Volume $\left(\mathrm{cm}^{3}\right)$

VI: Vascularization Index (\%)

FI: Flow Index

VFI: Vascularization Flow Index (VFI)

a Statistically significant results $(P<0.05)$

b Tukey's HSD (Honestly Significant Difference) test: to enable multiple comparisons across groups following a significant ANOVA test. This analysis demonstrated lowest mean $\mathrm{FI}$ in the obese group in both the first $(35.7, \mathrm{P}<0.001)$ and second $(39.4, \mathrm{P}<0.001)$ trimester. In addition, there were significant differences in mean PV when comparing the obese $\left(235.6 \mathrm{~cm}^{3}\right)$ and autoimmune groups $\left(174.7 \mathrm{~cm}^{3}\right) ; \mathrm{P}=0.002$. Sub-group analysis showed that mean $\mathrm{PV}$ was lower in women with diabetes who later developed $\mathrm{PE}$ in comparison to those who did not $\left(33.7(6.0) v 52.2(15.9) \mathrm{cm}^{3}, \mathrm{P}=0.03\right.$. In the hypertensive group, women with $\mathrm{PE}$ had significantly lower mean values of $\mathrm{VI}(8.7 v 15.6 \%, \mathrm{P}=0.03)$ and $\mathrm{VFI}(2.5 \quad v \quad 7.5, \mathrm{P}=0.03)$ in the first trimester. 
